\title{
MAPEANDO RELIGIÃO NA CIDADE: REFLEXÓES SOBRE A CRIAÇÃO DE TEMPLOS RELIGIOSOS NA CIDADE DO RIO DE JANEIRO ENTRE 2006 E 2016
}

\author{
Amanda Lacerda Jorge \\ André Augusto Pereira Brandão \\ Christina Vital da Cunha ${ }^{1}$
}

Resumo: Neste artigo temos como objetivo apresentar uma análise preliminar de dados sobre a criação de templos religiosos na cidade do Rio de Janeiro entre os anos 2006 e 2016. A partir da divulgação deste material buscamos contribuir para a qualificação e ampliação dos debates e investigaçôes acerca do crescente conflito religioso no contexto urbano no Brasil hoje, sobretudo em suas periferias. Os números e informaçóes aqui disponibilizados foram produzidos no âmbito do projeto de extensão e pesquisa intitulado "Promoção e Defesa da Liberdade Religiosa", vinculado à Pró-Reitoria de Extensão da Universidade Federal Fluminense. A pesquisa, ao centrar-se no caso do Rio de Janeiro, estado com o maior número de registros de Intolerância Religiosa no país, segundo dados do relatório da Secretaria Especial de Direitos Humanos, pretendeu incentivar uma reflexão que leve em conta as atuais interfaces entre violência, territorialidade e religião no país.

Palavras-chave: Religião; Templos; Rio de Janeiro; Intolerância Religiosa.

\section{MAPPING RELIGION IN THE CITY: REFLECTIONS ON THE CREATION OF RELIGIOUS TEMPLES IN THE CITY OF RIO DE JANEIRO \\ BETWEEN 2006 AND 2016}

\begin{abstract}
In this article we present a preliminary analysis of data on the creation of religious temples in the city of Rio de Janeiro between 2006 and 2016. From the dissemination of this material we seek to contribute to the qualification and expansion of the debates and investigations about the growing religious conflict in

1 Amanda Lacerda Jorge é doutora em Ciências Sociais pela Universidade Federal Fluminense, Rio de Janeiro, Brasil. E-mail: amandalacerdajorge@hotmail.com. André Augusto Pereira Brandáo é docente na mesma Universidade. E-mail: andre_brandao@id.uff. br. Christina Vital da Cunha é também docente da Universidade Federal Fluminense. E-mail: chrisvital10@gmail.com.
\end{abstract}

Debates do NER, Porto Alegre, Ano i9, N. 36, P. 237-265, Ago./Dez. 20 i 9 
the urban context in Brazil today, especially in its peripheries. The numbers and information provided here were produced within the scope of the extension and research project titled "Promotion and Defense of Religious Freedom", linked to the Pro-Rectory of Extension of the Federal Fluminense University. According to the report of the Special Secretariat for Human Rights, the study focused on the case of Rio de Janeiro, which had the highest number of Religious Intolerance records in the country. It aimed to encourage reflection that takes into account the current interfaces between violence, territoriality and religion in the country.

Keywords: Religion; Temples; Rio de Janeiro; Religious Intolerance.

\section{INTRODUÇÃO}

Neste artigo temos como objetivo apresentar uma análise preliminar de dados resultantes de uma pesquisa que visava quantificar a criação de templos religiosos na cidade do Rio de Janeiro entre os anos 2006 e 2016, produzindo alguma comparabilidade com dados existentes sobre outros períodos (Fernandes, 1992; Jacob; Hees; Waniez, 2013) na mesma cidade.

A partir da divulgação deste material buscamos contribuir para a qualificação e ampliação dos debates e investigações acerca do crescente conflito religioso no contexto urbano brasileiro atual, sobretudo em suas periferias. Os números e informaçóes disponibilizados neste trabalho foram produzidos no âmbito do projeto de extensão e pesquisa intitulado "Promoção e Defesa da Liberdade Religiosa”, vinculado à Pró-Reitoria de Extensão da Universidade Federal Fluminense.

O projeto ao centrar-se no caso do Rio de Janeiro, estado com o maior número de registros de Intolerância Religiosa no país, segundo dados do relatório da Secretaria Especial de Direitos Humanos², pretendeu incen-

2 O relatório é fruto de uma parceria entre a Comissão de Combate à Intolerância Religiosa (CCIR), Centro de Articulação de Populaçôes Marginalizadas (CEAP) e Laboratório de História das Experiências Religiosas (LHER) do Instituto de História da Universidade Federal do Rio de Janeiro (UFRJ). 
tivar uma reflexão que levasse em conta as atuais interfaces entre violência, territorialidade e religião no país e o fizemos a partir das diversas atividades promovidas ao longo dos anos de 2016 e 2017 no estado do Rio de Janeiro, resultado da parceria entre a Universidade Federal Fluminense e a Fundação Cultural Palmares. A construção de um banco de dados para o mapeamento de locais de culto no município do Rio de Janeiro fez parte deste rol de açôes propostas inicialmente. Portanto neste artigo, além da divulgação dos dados da pesquisa que ocorreu no âmbito do projeto "Promoção e Defesa da Liberdade Religiosa”, pretendemos destacar o percurso metodológico utilizado no tratamento e análise dos dados com vistas a incentivar a replicação destes mecanismos para a quantificação de templos religiosos em outras cidades e estados da federação.

Para tanto, inicialmente, recorremos à classificação proposta por Fernandes (1992) no conhecido Censo Institucional Evangélico - CIN 1992, para a criação de tipologias que nos permitissem identificar os locais de cultos no município do Rio de Janeiro. A classificação proposta pelo autor, fundada em sua longa experiência de pesquisa e nos debates acadêmicos nas Ciências Sociais no período, tinha como critérios cronologia, liturgia, relaçóes ecumênicas e doutrina (Fernandes, 1992, p. 23).

O modelo de análise construído por Jacob, Hees e Waniez (2013), no qual se apresenta a geografia da filiação religiosa no Brasil através de indicadores sociais e demográficos da população em diferentes regiōes do país, também nos serviu de inspiração. Neste caso, os dados do Censo Demográfico Nacional realizado pelo IBGE em 2010 foram fundamentais para os autores delimitarem espacialmente onde as confissóes religiosas estavam dispostas no território brasileiro.

Ainda em termos teórico-metodológicos tivemos como referência os trabalhos de Almeida (2004) e Almeida e Montero (2001) que analisam o trânsito religioso no Brasil refletindo sobre características sociodemográficas e sobre estratégias de localização de templos na cidade de São Paulo. 


\section{CONSTRUINDO UMA METODOLOGIA PARA O MAPEAMENTO SOBRE A CRIAÇÃO DE TEMPLOS RELIGIOSOS}

Iniciamos o trabalho de recolhimento de informaçóes sobre a criação de templos religiosos no Diário Oficial do Município do Rio de Janeiro (D.O.M), mapeando a publicação dos registros de estatutos de organizaçóes religiosas. A princípio, nosso propósito era cobrir a criação de templos na cidade do Rio de Janeiro e Região Metropolitana. Dado o grande volume de registros somente para o Rio, tivemos de limitar o escopo da pesquisa somente a este município com um recorte temporal de criação dos locais de culto $^{3}$. Ainda assim, foi necessária a mobilização de colaboradores externos à equipe inicial da pesquisa ${ }^{4}$ para coletarmos as centenas de registros realizados no período de 2006 a 2016, além de posteriormente classificar as organizaçóes criadas entre estes anos. Um passo a passo se fazia necessário, e o conhecimento da legislação vigente era imprescindível.

A Lei no 10.825, de 2003 (BRASIL, 2003), define as organizaçôes religiosas como pessoas jurídicas de direito privado ${ }^{5}$. Este dispositivo institui que tais organizaçóes possuem o direito de serem reconhecidas pelo Estado que deve garantir a estas liberdade de criação, estruturação e funcionamento. As organizações religiosas são caracterizadas, assim, como local de culto, de instrução de seus membros e fiéis, de atividades beneficentes entre outras ligadas à esfera religiosa ${ }^{6}$. Para serem reconhecidas como "pessoa jurídica de

3 A delimitação dos anos a serem cobertos na pesquisa de mapeamento se deveu, principalmente, aos anos 2000/2010 corresponderem a um período cujo crescimento do debate sobre Intolerância Religiosa gerou uma série de açóes nos âmbitos da sociedade civil e do Estado visando ao seu combate.

4 Agradecemos ao DataUff pela colaboração na formulação e preenchimento do banco de dados da pesquisa.

5 Sobre uma recente discussão comparativa entre Brasil, México, Uruguai e Argentina sobre processos de legalização do religioso ver Giumbelli (2017).

6 Com vistas à realização do mapeamento, foram contabilizados, somente, os lugares de culto religioso como terreiros, igrejas, e sinagogas, dentre outros. 
direito privado" precisam estar legalmente instituídas, o que ocorre através do registro em cartório de seu estatuto, acompanhado da ata da assembleia de sua fundação. Estes documentos devem ser apresentados em um Cartório de Registro de Pessoa Jurídica (CRPJ). Com esta documentação em ordem é que o cartório realiza os trâmites necessários para o lançamento da certidão de registro.

No município do Rio de Janeiro, foi possível encontrar a publicação do registro destes estatutos no Diário Oficial do Município. Vale lembrar que o Diário Oficial tem como objetivo dar publicidade aos atos da esfera executiva, legislativa ou judiciária de interesse do cidadáo. A primeira fonte de informações para a pesquisa veio do D.O.M., especificamente na parte de "publicaçôes a pedido", onde estão registradas atas, estatutos, certidóes, avisos, editais. Foram, então, os registros dos estatutos das organizaçóes religiosas que nos deram as pistas iniciais sobre a criação de templos na cidade.

Assim, no site do Diário Oficial do Município do Rio de Janeiro (http:// doweb.rio.rj.gov.br/), a busca foi feita pelo registro de estatutos das instituiçôes religiosas, utilizando a ferramenta de busca com a palavra-chave "estatuto". A pesquisa nos direcionava para uma lista de links que correspondiam a cada dia de publicação no intervalo de tempo proposto. Ao abrir o link, procurávamos pela palavra chave selecionada e então encontrávamos a lista nominal das instituiçóes, data de publicação do registro e, em alguns casos, o endereço da organização religiosa.

No que tange ao caminho de legalização das organizaçôes religiosas, há outro passo a ser concretizado: o registro na Receita Federal, pela via do Cadastro Nacional de Pessoa Jurídica (CNPJ). Este ato, além de regular o funcionamento, permite que a organização religiosa realize legalmente transaçôes financeiras ou administrativas, por exemplo. Para tanto, é necessário que a instituição apresente à Receita Federal, o estatuto e ata da assembleia de sua aprovação já registrados em Cartório ou ainda, no caso da Igreja Católica, especificamente, a apresentação de documento emitido pela administração central da mesma, acompanhado do ato de designação do titular da respectiva representação, também registrados (BRASIL, [201-]). 
É interessante ressaltar que tem crescido nos últimos anos a divulgação de informaçôes - na forma de cartilhas, principalmente - para que os locais de práticas religiosas de matriz africana também se instituam como sujeito de direito privado. Uma cartilha divulgada pela Secretaria de Assistência Social e Direitos Humanos do Estado do Rio de Janeiro em 2012, traz o debate sobre a invisibilidade destes segmentos religiosos, sobre a intolerância religiosa sofrida pelos mesmos e sobre a importância de se estabelecer direitos e deveres para terreiros e demais espaços de cultos de matriz africana. A cartilha traz também, explicaçóes detalhadas acerca de como efetivar a legalizaçáo destes espaços.

Ou seja, independente da organização religiosa, o estatuto é um documento importante, pois tem como objetivo descrever os fundamentos e diretrizes da instituição religiosa. Após a criação, aprovaçấo e registro do estatuto, podemos afirmar que é o CNPJ o responsável por atribuir uma identidade burocrática à pessoa jurídica, neste caso, à organizaçáo religiosa.

No cadastro realizado na Receita Federal, algumas informaçóes, são exigidas - data de abertura da instituiçáo, nome (Razão Social ou fantasia), código e descrição das atividades, descrição da natureza jurídica e endereço. Estes elementos fazem parte da caracterizaçáo da instituiçáo como uma organizaçáo religiosa. Tais variáveis, presentes no cadastro nacional de pessoa jurídica (CNPJ) da Receita Federal, podem ser pesquisadas em sites de busca de CNPJ como: empresas.com, empresasdorj.com e empresasdobrasil.com - foi desta forma que levantamos informaçôes mais específicas sobre estas organizaçóes. O conjunto de dados coletados no Diário Oficial do Município do Rio de Janeiro e nos sites de busca de CNPJ foram digitados em uma ficha eletrônica previamente padronizada que, posteriormente, foi exportada para um banco de dados. Logo a seguir, podemos verificar a ficha de coleta de dados utilizada. Vale ressaltar que um número expressivo de locais de culto foi encontrado durante a pesquisa nestes sites de busca, embora não tenhamos localizado sua publicação no Diário Oficial do Município. O subregistro de templos religiosos é bastante comum em favelas e periferias (CIN 1992) e, especialmente, entre religiôes afrobrasileiras como apontam 
alguns estudos (Silva Jr., 2009; Fonseca; Giacomini, 2013; Rego; Fonseca; Giacomini, 2014; PUC-Rio; SEASDH-RJ, 2012).

Quadro 1 - Exemplo de ficha de coleta de dados com informaçôes das organizaçôes religiosas

CNPJ: 10.492.926/0001-03

Razão Social: COMUNIDADE CRISTÃ NOVA VIDA DO BRASIL

Nome Fantasia: não tem

Data de Abertura: 11/11/2008

Natureza Jurídica: 399-9 - Associação Privada

Atividade Principal: 94.91-0-00 - Atividades de organizações religiosas ou filosóficas

Endereço:

CEP: 21.031-700

Logradouro: R JOAO ROMARIZ

Número: 47

Complemento:

Bairro: RAMOS

Município: RIO DE JANEIRO

UF: RJ

Fonte: Elaborado pelos autores.

Outra fonte de coleta de informaçôes para a pesquisa foi o Anuário Católico (ARQUIDIOCESE DE SÃO SEBASTIÃO DO RIO DE JANEIRO, 2015) publicado pelo Centro de Estatística Religiosa e Investigaçôes Sociais (CERIS) do ano de 2015. Trata-se do levantamento mais recente realizado pela Igreja Católica. Neste documento estão disponibilizados os nomes, endereços e datas de fundação de paróquias até o final do ano de 2015 em todo o território brasileiro. No entanto, o ano de criaçáo de capelas, igrejas e santuários que estão sobre a jurisdição territorial das paróquias, não está disponível neste anuário de maneira detalhada. Foi possível verificar neste documento que estáo registradas no munícipio do Rio de Janeiro 265 paróquias, e vinculados a estas estão, aproximadamente, 1400 espaços de cultos.

Debates do NER, Porto Alegre, Ano i9, N. 36, P. 237-265, Ago./Dez. 20 i 9 
Como não era possível obter o ano de criação de capelas, igrejas e santuários no Anuário, recorremos a ligaçóes telefônicas para a Cúria da Arquidiocese do estado do RJ e também para as paróquias listadas no documento para levantar as informaçóes necessárias para a construção do banco de dados. No entanto, grande parte das paróquias não atendia às ligaçôes ou, quando atendia, não possuía as informaçôes que demandávamos. Como resultado obtivemos dados relativos à criação de espaços de culto católicos em 225 (das 265 paróquias) a partir de 2006. Neste sentido, destacamos que a Igreja Católica poderá estar sendo representada no banco de dados com um número de templos menor do que os que foram abertos no período.

\section{A CONSTRUÇÃo DO BANCO DE DADOS E A PRODUÇÃo DE TIPOLOGIAS}

No banco de dados, base de informaçóes da pesquisa de mapeamento, trabalhamos com as seguintes variáveis: CNPJ, nome da organização religiosa, bairro, zona geográfica, atividade econômica principal, natureza jurídica, data de publicação do estatuto, ano de abertura da instituição e endereço (logradouro, número e complemento). Além destas variáveis, buscamos produzir tipologias que nos permitissem organizar a apresentação dos espaços de culto ligados às diferentes religiôes, assim como identificar se os templos criados no período delimitado pela pesquisa estavam em favelas.

E quanto ao uso de tipologias? No âmbito das Ciências Sociais, podemos afirmar que as tipologias têm como objetivo organizar, agrupar elementos e informaçóes, ao buscar aproximaçôes possíveis frente à diversidade de elementos que compóem um determinado contexto de interesse para a análise. Sua construção é um processo dinâmico e interpretativo que dialoga com a produçáo especializada já existente e com a singularidade de seus objetivos de pesquisa. Neste sentido, as tipologias deveriam nos possibilitar: 1) agrupar os espaços de culto em termos doutrinários/sociais; 2) além de referenciá-los no mapa da cidade, ou seja, nos diferentes bairros do município do Rio de Janeiro. 
Para mapear os espaços de culto foi necessário classificar os 158 bairros listados no banco de dados em um conjunto de zonas geográficas utilizadas pelos órgãos oficiais do município (RIO DE JANEIRO, 2017). Sendo assim, os bairros foram divididos em zonas: Sul, Norte, Central, Oeste. No caso da Zona Oeste estabelecemos uma separação especificamente definida a partir de nossos interesses de pesquisa entre: a) uma área em que há tendência de maior presença de população com renda elevada e; b) outra onde há tendência oposta. Com isto, separamos a Zona Oeste 1 (composta especificamente pela Barra da Tijuca e pelo Recreio dos Bandeirante cujo nível de renda é maior) em relação aos bairros contidos na Zona Oeste 2 (integrada pelos bairros de Bangu, Realengo, Jacarepaguá).

Obviamente esta classificação ${ }^{7}$ em zonas não esgota todas as variáveis que circundam o fenômeno em análise e muito menos garantem homogeneidade socioeconômica em cada uma destas. Um espaço de culto religioso situado na Zona Sul ou na Zona Oeste 1, áreas com tendência a apresentar indicadores socioeconômicos mais elevados, pode estar especificamente localizado em uma favela ou espaço correlato que apresente indicadores opostos ao do conjunto da região. Da mesma forma, um local de culto religioso situado na Zona Norte (onde tendencialmente encontraríamos indicadores socioeconômicos mais baixos), pode ter como endereço uma área de classe média e indicadores sociais mais elevados como algumas regiôes do bairro da Tijuca.

Enfim, a organização dos endereços por zonas definidas na cidade do Rio de Janeiro nos possibilitou identificar tendências geoespaciais. Com isto, tornou-se possível estabelecer uma correlação aproximada entre estas tendências, as variáveis socioeconômicas mais amplas e os locais de culto religioso.

7 A classificação das zonas foi construída a partir do índice de desenvolvimento social de bairros e favelas do município do Rio de Janeiro. Disponível em: http://portalgeo. rio.rj.gov.br/estudoscariocas/download/2394_\%C3\%8Dndice\%20de\%20Desenvolvimento\%20Social_IDS.pdf. Acesso em: 3 fev. 2019.

Debates do NER, Porto Alegre, Ano i9, N. 36, P. 237-265, Ago./Dez. 20 i 9 
Maior refinamento conseguimos ao efetuar uma segunda classificação. Esta foi construída tomando como base o georreferenciamento do endereço completo dos locais de culto religioso identificados e a comparação dos pontos geográficos gerados através de mapas elaborados e disponibilizados publicamente pela prefeitura do Rio de Janeiro que identificam as áreas do município caracterizados como "aglomerados subnormais".

Tal nomenclatura, segundo o IBGE, "engloba os diversos tipos de assentamentos irregulares existentes no país, como favelas, invasốes, grotas, baixadas, comunidades, vilas, ressacas, mocambos, palafitas, entre outros" (IBGE, 2010a).

Esta segunda classificação, portanto, somente identifica se um dado local de culto está ou não situado em uma área de favela. No entanto, mais uma vez, trata-se de uma aproximaçáo posto que, apesar dos mapas utilizados como base datarem do ano de 2016, a dinâmica da ocupação territorial da cidade tende a provocar alteraçôes no número, dispersão e tamanho dos "aglomerados subnormais".

8 Segundo o IBGE, um aglomerado subnormal corresponde a um conjunto constituído de, no mínimo, 51 unidades habitacionais em sua maioria carentes de serviços públicos essenciais, ocupando ou tendo ocupado, até período recente, terreno de propriedade alheia (pública ou particular) e estando dispostas, em geral, de forma desordenada el ou densa. A identificação dos aglomerados subnormais é feita com base nos seguintes critérios: a) Ocupação ilegal da terra, ou seja, construção em terrenos de propriedade alheia (pública ou particular) no momento atual ou em período recente (obtenção do título de propriedade do terreno há dez anos ou menos); e b) Possuir pelo menos uma das seguintes características: • urbanização fora dos padróes vigentes - refletido por vias de circulação estreitas e de alinhamento irregular, lotes de tamanhos e formas desiguais e construçóes não regularizadas por órgãos públicos; ou • precariedade de serviços públicos essenciais, tais quais energia elétrica, coleta de lixo e redes de água e esgoto. Os aglomerados subnormais podem se enquadrar, observados os critérios de padróes de urbanização e/ou de precariedade de serviços públicos essenciais, nas seguintes categorias: invasão, loteamento irregular ou clandestino, e áreas invadidas e loteamentos irregulares e clandestinos regularizados em período recente. (IBGE, 2010a, p. 18). 
Como foi realizado este georreferenciamento? Com base no banco de dados contendo as informacôes sobre as instituiçóes religiosas criadas entre os nos anos de 2006 e 2016, utilizamos alguns programas específicos para o processamento geográfico ${ }^{9}$ Todas as informaçóes adquiridas neste processamento foram transformadas em pontos específicos em um mapa a partir dos campos "logradouro", "número" e "bairro". Após esta etapa, utilizamos as tipologias para filtrar e diferenciar os espaços de culto por zonas geográficas.

Em um segundo momento, buscamos identificar locais de cultos situados em favelas. Para isso, utilizamos a "mancha" das favelas do ano de 2016 do município do Rio de Janeiro. O resultado deste último procedimento pode ser observado na tabela 1 logo a seguir. Como vemos, somente locais de culto evangélicos e afro-brasileiros foram criados em áreas que identificamos como favela no período abarcado pela pesquisa.

Tabela 1 - Percentual de templos criados entre 2006 e 2016 em áreas de favela no município do Rio de Janeiro

\begin{tabular}{cccc}
\hline $\begin{array}{c}\text { Vinculaçáo } \\
\text { religiosa }\end{array}$ & $\begin{array}{c}\mathbf{N}^{\circ} \text { de locais de culto } \\
\text { criados em áreas de favela }\end{array}$ & $\begin{array}{c}\text { Total de locais } \\
\text { de culto criados }\end{array}$ & $\begin{array}{c}\text { \% de locais de culto criados } \\
\text { em áreas de favela }\end{array}$ \\
\hline Evangélico & 488 & 3537 & $13,80 \%$ \\
Afro-brasileiro & 11 & 231 & $4,76 \%$ \\
\hline
\end{tabular}

Fonte: Pesquisa Promoção e Defesa da Liberdade Religiosa - Fundação Cultural Palmares e Universidade Federal Fluminense.

No tocante à caracterização dos lugares de culto conforme religióes e correntes internas as mesmas (quando náo se tratavam de denominaçóes referidas e classificadas na bibliografia especializada), foi necessário um esforço específico - para tanto, nos apoiamos em diferentes referenciais

9 Para o georreferenciamento foram utilizados os softwares QGIS e Google Earth. Também foram úteis as informaçôes sobre bairros e zonas geográficas do município do Rio de Janeiro disponíveis no site www.armazemdedados.rio.rj.gov.br. Foi pesquisada, além disso, a localização geográfica de favelas no site do Instituto Pereira Passos (IPP, 2014).

Debates do NER, Porto Alegre, Ano i9, N. 36, P. 237-265, Ago./Dez. 20 i 9 
metodológicos e especializados no tema da religiáo. Para o primeiro caso, tomamos como referência ampla a proposta de Ginzburg (1989) relativa ao que o autor denomina como paradigma indiciário. Trata-se de utilizar um conjunto de detalhes, sinais e indícios que poderiam ser tomados mesmo como "negligenciáveis" para descrever ou classificar uma "realidade complexa" que não foi experimentada diretamente pelo sujeito da investigação (Ginzburg, 1989, p. 152).

Obviamente tal perspectiva enseja elevado grau de subjetividade no que tange aos indícios e detalhes selecionados e a forma de interpretação destes. De fato, os indícios nos possibilitaram chegar a construção de um conjunto de "tipos ideais". No sentido weberiano do termo, questão básica do conhecimento nas ciências sociais, o "tipo ideal" corresponde a um modelo teórico construído a partir de fenômenos isolados ou da relaçáo entre estes com vistas a ser testado empiricamente. Na obra "A objetividade do conhecimento nas ciências sociais”, Weber (1985, p. 109) define o tipo ideal:

Trata-se [...] de um quadro de pensamento, não da realidade histórica, e muito menos da realidade "autêntica"; náo serve de esquema em que se possa incluir a realidade à maneira de exemplar. Tem, antes, o significado de um conceito-limite, puramente ideal, em relação ao qual se mede a realidade a fim de esclarecer o conteúdo empírico de alguns dos seus elementos importantes, e com o qual é comparada. Tais conceitos são configuraçóes nas quais construímos relaçóes, por meio da utilização da categoria de possibilidade objetiva, que a nossa imaginação, formada e orientada segundo a realidade, julga adequadas.

Como se depreende da citação acima, o tipo ideal não corresponde a uma descrição, nem a uma hipótese. Também não é ideal em sentido normativo, mas sim um "tipo puro" em sentido lógico. Por outro lado, a construção de tipos ideais não corresponde ao objetivo da pesquisa, mas sim a um recurso para viabilizar a análise da realidade empírica. Isto se faz por meio da "acentuação unilateral" de um ponto ou de vários pontos de vista e do "encadeamento de grande quantidade de fenômenos isoladamente 
dados" e difusos, "que se ordenam segundo os pontos de vista unilateralmente acentuados, a fim de se formar um quadro homogêneo de pensamento" (Weber, 1985, p. 106).

Frente a esta saída metodológica informada, por um lado, pela noção weberiana de tipo ideal e, por outro lado, pela procura de indícios e detalhes derivados de uma realidade excessivamente complexa, chegamos a elaboração de três tipologias relativas ao enquadramento religioso dos locais de culto mapeados. Uma primeira, que contém 17 variáveis é mais ampla e tendencialmente mais sujeita a possibilidade de imprecisóes. A segunda com 11 variáveis é mais restrita e potencialmente carrega menores riscos classificatórios que a anterior. E por fim, a tipologia de número três repete em linhas gerais a primeira.

A única diferença é que nesta os locais de culto evangélicos que se referiam à filiação tradicional, mas que haviam sido classificados como pentecostais anteriormente, foram reclassificados como evangélicos tradicionais renovados (entre estas encontramos as denominaçóes batista, metodista e presbiteriana já pentecostalizadas, por exemplo). O objetivo desta terceira tipologia é, simplesmente, identificar os "renovados" na massa de pentecostais. Um exemplo é o espaço de culto "Associação Batista Adonai”, ou ainda a "Comunidade Presbiteriana da Freguesia". Logo a seguir, apresentamos o quadro com as tipologias construídas.

Quadro 2-Tipologias

\begin{tabular}{|c|c|c|}
\hline Tipologia detalhada & $\begin{array}{c}\text { Tipologia menos } \\
\text { detalhada }\end{array}$ & $\begin{array}{c}\text { Tipologia mais detalhada } \\
\text { com separaçáo das igrejas } \\
\text { evangélicas renovadas }\end{array}$ \\
\hline $\begin{array}{c}\text { Afro-brasileiro } \\
\text { náo identificado }\end{array}$ & Afro-brasileiro & $\begin{array}{c}\text { Afro-brasileiro } \\
\text { náo identificado }\end{array}$ \\
\hline Budista & Budista & Budista \\
\hline Candomblé & Católico & Candomblé \\
\hline Católico & Espírita & Católico \\
\hline
\end{tabular}

Debates do NER, Porto Alegre, ano i9, N. 36, P. 237-265, Ago./Dez. 2019 
Quadro 2 (cont.)

\begin{tabular}{|c|c|c|}
\hline Tipologia detalhada & $\begin{array}{c}\text { Tipologia menos } \\
\text { detalhada }\end{array}$ & $\begin{array}{c}\text { Tipologia mais detalhada } \\
\text { com separaçáo das igrejas } \\
\text { evangélicas renovadas }\end{array}$ \\
\hline Cristáo Ortodoxo & Evangélico & Cristáo Ortodoxo \\
\hline Espírita Kardecista & Hinduísta & Espírita Kardecista \\
\hline Espírita não identificado & Islâmico & Espírita náo identificado \\
\hline Evangélico Tradicional & Judaico & Evangélico pentecostal \\
\hline Evangélico náo identificado & Maçônico & Evangélico náo identificado \\
\hline Evangélico pentecostal & Outros & Evangélico tradicional \\
\hline Hinduísta & Outros Cristáos & $\begin{array}{c}\text { Evangélico Tradicional } \\
\text { Renovado }\end{array}$ \\
\hline Islâmico & ---- & Hinduísta \\
\hline Judaico & ---- & Islâmico \\
\hline Maçônico & ---- & Judaico \\
\hline Outros & --- & Maçônico \\
\hline Santo Daime & ---- & Outros \\
\hline Umbanda & ---- & Santo Daime \\
\hline ---- & ---- & Umbanda \\
\hline
\end{tabular}

Fonte: Pesquisa Promoção e Defesa da Liberdade Religiosa - Fundação Cultural Palmares e Universidade Federal Fluminense.

Após a apresentação das tipologias criadas para a nossa análise, cabe aqui explicarmos melhor a criação destas, começando com o grupo dos evangélicos. A primeira etapa deste trabalho de classificação se voltava para o nome de registro do local de culto mapeado. Assim um local com a razáo social "IGREJA EVANGÉLICA PENTECOSTAL MINISTÉRIO DEUS É GRANDE" já indicava se tratar de uma igreja evangélica de viés pentecostal. Já um local nomeado como "IGREJA EVANGÉLICA DA CONQUISTA" trazia a certeza do caráter evangélico, somente. No primeiro caso, onde havia 
uma nomeação direta do enquadramento religioso, compomos a tipologia mais detalhada com a identificação do local de culto como "evangélico pentecostal" e a tipologia menos detalhada com a identificação como local de culto "evangélico".

No segundo caso, a razão social por si só nos permitia preencher a coluna referente à tipologia menos detalhada (como "evangélico"), mas não a tipologia mais detalhada. A coleta de indícios e sinais se impunha como ferramenta - assim, frente à impossibilidade de visitar cada um dos espaços de culto não passíveis de classificação pela razão social registrada, buscávamos informações referentes a estes na web, seja através de perfis de Facebook, de blogs ou de sites. Nestes, fazíamos a leitura de textos, assistíamos a vídeos postados que em geral mostravam atividades religiosas, observávamos as fotos anexadas, líamos posts, com vistas a localizar "cronologias, liturgias, relaçóes ecumênicas e doutrinas" (Fernandes, 1992, p. 23) que nos permitissem identificar as igrejas sob a égide das classificaçóes consagradas no campo de estudos da religião (Freston, 1994; Mariano, 1999; Fernandes, 1992). Nos casos em que não conseguíamos classificar o local de culto evangélico por seu nome de registro e não encontrávamos qualquer possibilidade de coletar indícios na web, classificamo-los de "Evangélico não identificado".

No que tange aos espaços de culto que se nomeavam como centros espíritas, e fraternidades adotamos procedimento semelhante buscando informações em sites, blogs e Facebook. Quando não conseguimos indícios que lhes vinculassem ao Kardecismo, apresentamo-los na classificação mais geral Espírita. Como se poderia inferir previamente, as interfaces entre candomblé e umbanda eram muitas e tal hibridismo tornava ainda mais desafiadora a nossa tentativa de classificação por registro dos lugares de culto, sem possibilidades de ir a campo. Sendo assim, em alguns casos era possível identificar pelo registro que se tratava de um espaço de culto da Umbanda, em outros nos quais os registros não deixavam isto claro e que não conseguíamos informaçôes na web, optamos pela classificação genérica "Afro-brasileiro não identificado". 
Encontramos ainda espaços de culto nomeados ou que foram identificados a partir de indícios encontrados após pesquisa na web, como Hinduísta, Budista, Cristão Ortodoxo, Maçonaria, Islâmico, Judaico e Santo Daime. Os locais de culto que não se enquadravam em nenhuma destas alternativas acima descritas foram classificados como "Outros".

\section{RESULTADOS INICIAIS DO USO DA TIPOLOGIA}

Apresentamos a seguir alguns resultados gerais que foram gerados a partir do banco de dados produzido. Como vemos, no período definido para a pesquisa identificamos a criaçáo de 3990 locais de culto religioso na cidade do Rio de Janeiro, o que representa mais de 1 local criado por dia na década.

Ao utilizar a tipologia mais geral verificamos a ampla maioria de locais evangélicos que correspondem a $88,65 \%$ do total. A elevada presença de instituiçôes evangélicas se opôe ao peso restrito das demais filiaçôes religiosas. Vários fatores colaboram na explicação deste fenômeno e a bibliografia especializada já lhes apresentou, tendo notável força a questão do tipo de gestão das igrejas que mais crescem (congregacional, logo, não centralizada), as constantes rupturas de líderes com as igrejas nas quais se formaram criando novas denominaçôes e as ambiçóes e disputas institucionais. As religióes afro-brasileiras tiveram um percentual de abertura de templos muito pequeno diante dos evangélicos. As consideraçóes sobre estes dados nos forçam a destacar que o baixo quantitativo náo é sinônimo de inoperância sociocultural desta tradiçâo. A descentralizaçáo própria da lógica destas religiôes, assim como o fato de não serem religióes de conversão, universalistas, de serem religióes chamadas do "segredo" contribuem para explicar estes percentuais. Chama a atenção, contudo, que nos anos finais do período coberto pela pesquisa haja um número maior de registros. Nossa hipótese é que este incremento seja fruto de políticas públicas e do trabalho incansável do movimento social na elaboraçáo de cartilhas orientando e incentivando ao 
registro de casas e terreiros, além de outras campanhas e ações que visam à valorização da identidade religiosa afro-brasileira.

Tabela 2 - Locais de culto religioso criados entre 2006 e 2016 no município do Rio de Janeiro, segundo tipologia menos detalhada

\begin{tabular}{lcc}
\hline \multicolumn{1}{c}{ Locais de culto religioso } & No de locais de culto religioso & $\%$ \\
\hline Evangélico & 3537 & $88,65 \%$ \\
Afro-brasileiro & 231 & $5,79 \%$ \\
Espírita & 71 & $1,78 \%$ \\
Católico & 62 & $1,55 \%$ \\
Outros & 62 & $1,55 \%$ \\
Judaico & 7 & $0,18 \%$ \\
Maçônico & 7 & $0,18 \%$ \\
Outros Cristáos & 5 & $0,13 \%$ \\
Islâmico & 3 & $0,08 \%$ \\
Hinduísta & 3 & $0,08 \%$ \\
Budista & 2 & $0,05 \%$ \\
\hline Total geral & $\mathbf{3 9 9 0}$ & $\mathbf{1 0 0 , 0 0 \%}$ \\
\hline
\end{tabular}

Fonte: Pesquisa Promoção e Defesa da Liberdade Religiosa - Fundaçáo Cultural Palmares e Universidade Federal Fluminense.

Na tabela 3, construída a partir da tipologia mais detalhada, é possível verificar o grande peso dos locais de cultos evangélicos pentecostais criados frente aos demais deste segmento (tradicionais e não identificados). O boom evangélico é, de fato, um boom pentecostal, conforme uma farta bibliografia apresenta (Teixeira; Menezes, 2006, 2013; Mafra, 2009, 2001; Pierucci, 2004, 2003; entre outros). Neste contexto é significativo o baixo percentual alcançado pelo segmento evangélico tradicional, como tendencialmente já revelavam pesquisas sobre o número de seus fiéis realizadas pelo IBGE, DataFolha e FGV. O segundo ponto a destacar diz respeito aos locais de culto afro-brasileiros. Verificamos que foram criados quase 5 vezes mais locais 
vinculados a umbanda do que ao candomblé. O número elevado de espaços afro-brasileiros que não foram passíveis de identificação (43) se deve ao fato de que no caso deste segmento, encontramos em menor medida adesão a blogs, Facebook e sites que pudessem oferecer maiores informaçôes. Um ethos do segredo que acompanha estas tradiçôes, junto ao já mencionado baixo número de registros cartoriais de seus templos nos ajuda a refletir sobre a pouca visibilidade nas mídias sociais, assim como o baixo número de templos capturáveis pela pesquisa neste período.

Tabela 3 - Número de locais de culto religioso criados entre 2006 e 2016 no município do Rio de Janeiro, segundo tipologia mais detalhada

\begin{tabular}{lcc}
\hline \multicolumn{1}{c}{ Locais de culto religioso } & No de locais de culto religioso & $\%$ \\
\hline Evangélico pentecostal & 3400 & $85,21 \%$ \\
Umbanda & 154 & $3,86 \%$ \\
Evangélico tradicional & 110 & $2,76 \%$ \\
Católico & 62 & $1,55 \%$ \\
Outros & 61 & $1,53 \%$ \\
Espírita Kardecista & 53 & $1,33 \%$ \\
Afro-brasileiro náo identificado & 43 & $1,08 \%$ \\
Candomblé & 34 & $0,85 \%$ \\
Evangélico não identificado & 27 & $0,68 \%$ \\
Espírita não identificado & 18 & $0,45 \%$ \\
Maçônico & 7 & $0,18 \%$ \\
Judaico & 7 & $0,18 \%$ \\
Cristáo Ortodoxo & 5 & $0,13 \%$ \\
Hinduísta & 3 & $0,08 \%$ \\
Islâmico & 3 & $0,08 \%$ \\
Budista & 2 & $0,05 \%$ \\
Santo Daime & 1 & $0,03 \%$ \\
\hline Total geral & 3990 & $\mathbf{1 0 0 , 0 0 \%}$ \\
\hline
\end{tabular}

Fonte: Pesquisa Promoção e Defesa da Liberdade Religiosa - Fundação Cultural Palmares e Universidade Federal Fluminense. 
A tabela 4 a seguir utiliza a classificação que separa os tradicionais renovados (que seguem padrôes litúrgicos pentecostalizados) da massa dos pentecostais. Vemos que este segmento específico apresenta o segundo maior percentual de criação de locais de culto na década, embora em índice muito inferior ao dos evangélicos pentecostais.

Tabela 4 - Número de locais de culto religioso criados entre 2006 e 2016 no município do Rio de Janeiro, segundo tipologia mais detalhada e separando os evangélicos tradicionais renovados

\begin{tabular}{lcc}
\hline \multicolumn{1}{c}{ Locais de culto religioso } & No de locais de culto religioso & $\%$ \\
\hline Evangélico pentecostal & 3174 & $79,55 \%$ \\
Evangélico Tradicional Renovado & 226 & $5,66 \%$ \\
(pentecostalizado) & & \\
Umbanda & 154 & $3,86 \%$ \\
Evangélico Tradicional & 110 & $2,76 \%$ \\
Católico & 62 & $1,55 \%$ \\
Outros & 61 & $1,53 \%$ \\
Espírita Kardecista & 53 & $1,33 \%$ \\
Afro-brasileiro năo identificado & 43 & $1,08 \%$ \\
Candomblé & 34 & $0,85 \%$ \\
Evangélico não identificado & 27 & $0,68 \%$ \\
Espírita náo identificado & 18 & $0,45 \%$ \\
Maçônico & 7 & $0,18 \%$ \\
Judaico & 7 & $0,18 \%$ \\
Cristão Ortodoxo & 5 & $0,13 \%$ \\
Islâmico & 3 & $0,08 \%$ \\
Hinduísta & 3 & $0,08 \%$ \\
Budista & 2 & $0,05 \%$ \\
Santo Daime & 1 & $0,03 \%$ \\
\hline Total geral & $\mathbf{3 9 9 0}$ & $\mathbf{1 0 0 , 0 0 \%}$ \\
\hline
\end{tabular}

Fonte: Pesquisa Promoção e Defesa da Liberdade Religiosa - Fundação Cultural Palmares e Universidade Federal Fluminense.

Debates do NER, Porto Alegre, ano i9, N. 36, P. 237-265, Ago./Dez. 20 ig 
Entre os locais de culto evangélico pentecostal se destacam aqueles nomeados como Assembleia de Deus. Nada menos que 1498 locais mapeados estão neste campo. A tabela 5 mostra que os templos da Assembleia de Deus criados correspondem a $44,07 \%$ do conjunto de templos pentecostais, e a $42,37 \%$ do conjunto de templos evangélicos em geral.

Este peso da Assembleia de Deus no conjunto dos evangélicos vem sendo apontado pela literatura da área. Almeida (2004) ao realizar o mapeamento de locais de culto na regiáo metropolitana de Sáo Paulo destaca a presença e construção de templos de duas denominaçôes pentecostais: Assembleia de Deus e Igreja Universal do Reino de Deus e mostra que o segmento evangélico pentecostal recebe cada vez mais adeptos entre os mais pobres desta região. Nas áreas de maior vulnerabilidade é possível verificar principalmente a presença da igreja Assembleia de Deus. Como exemplo, cita a presença de oito templos na favela de Paraisópolis.

Já os templos da Igreja Universal estấo concentrados principalmente nas vias principais, como estratégia de visibilidade e marketing. $\mathrm{O}$ mesmo acontece com as paróquias católicas - localizadas principalmente no interior dos bairros da regiáo metropolitana de Sáo Paulo, em vias principais (Almeida, 2004).

Jacob, Hees e Waniez (2013) mostram que, entre 1991 e 2010, o número de adeptos da Assembleia de Deus no Brasil passou de 29,8\% para $48,5 \%$ do total de evangélicos pentecostais. No entanto, é preciso que tenhamos cuidado com estes resultados, uma vez que a presença da nomeação Assembleia de Deus na razão social de um dado local de culto não significa que exista homogeneidade institucional. Isto porque, apesar desta denominação ter sido utilizada pela primeira vez em 1911, quando da criação da primeira igreja no estado do Pará, atualmente esta corresponde a um vastíssimo rol de ministérios, alguns concorrentes entre si, cujo tempo de fundação, lideranças religiosas, volume de fieis e número de templos são muito distintos. Parte destes locais está vinculado e obedece a princípios de uma das convençốes nacionais existentes. 
Tabela 5 - Percentual de templos da Assembleia de Deus criados entre 2006 e 2016 no município do Rio de Janeiro no conjunto dos templos evangélicos pentecostais e evangélicos em geral

\begin{tabular}{ccccc}
\hline $\begin{array}{c}\text { Locais de culto } \\
\text { denominados } \\
\text { Assembleia de } \\
\text { Deus }\end{array}$ & $\begin{array}{c}\text { \% de locais de } \\
\text { culto denominados } \\
\text { Assembleia de Deus } \\
\text { entre os evangélicos } \\
\text { pentecostais }\end{array}$ & $\begin{array}{c}\text { Locais de culto } \\
\text { evangélicos } \\
\text { pentecostais }\end{array}$ & $\begin{array}{c}\text { \% de locais de } \\
\text { culto denominados } \\
\text { Assembleia de Deus } \\
\text { entre os evangélicos } \\
\text { em geral }\end{array}$ & $\begin{array}{c}\text { Locais de culto } \\
\text { evangélicos em } \\
\text { geral }\end{array}$ \\
\hline 1498 & 44,06 & 3400 & 42,35 & 3537 \\
\hline
\end{tabular}

Fonte: Pesquisa Promoção e Defesa da Liberdade Religiosa - Fundação Cultural Palmares e Universidade Federal Fluminense.

A distribuição dos 3990 espaços de culto religiosos criados entre 2006 e 2016, pelas zonas geográficas previamente definidas pode ser observada na tabela 6 , logo abaixo. Há amplo predomínio da criação destes locais na Zona Oeste 2, que se apresenta como área de expansão urbana no contexto do município e compreende população tendencialmente de menor renda. Em seguida, vemos a Zona Norte, que também contém população em geral mais pobre, mas que não se mantém como área de expansão.

Tabela 6 - Distribuição percentual dos locais de culto criados entre 2006 e 2016, segundo a zona geográfica no município do Rio de Janeiro

\begin{tabular}{lcc}
\hline \multicolumn{1}{c}{ Zonas geográficas } & Número de locais de culto criados & \% \\
\hline Zona Sul & 118 & $2,96 \%$ \\
Zona Central & 107 & $2,68 \%$ \\
Zona Norte & 1519 & $38,07 \%$ \\
Zona Oeste 1 & 84 & $2,11 \%$ \\
Zona Oeste 2 & 2128 & $53,33 \%$ \\
Não identificada & 34 & $0,85 \%$ \\
\hline Total geral & $\mathbf{3 9 9 0}$ & $\mathbf{1 0 0 \%}$ \\
\hline
\end{tabular}

Fonte: Pesquisa Promoção e Defesa da Liberdade Religiosa - Fundação Cultural Palmares e Universidade Federal Fluminense. 
A tabela 7, complementando a anterior, mostra que dos quatro segmentos evangélicos, três possuem mais da metade dos locais de culto criados no período, localizados especificamente na Zona Oeste 2. Estes segmentos são: evangélicos pentecostais, evangélicos tradicionais e evangélicos tradicionais renovados. Ou seja, a área que ainda possui características de expansão urbana no contexto da cidade do Rio de janeiro, é exatamente onde os evangélicos dispuseram mais da metade de seus locais de culto criados entre 2006 e 2016. 


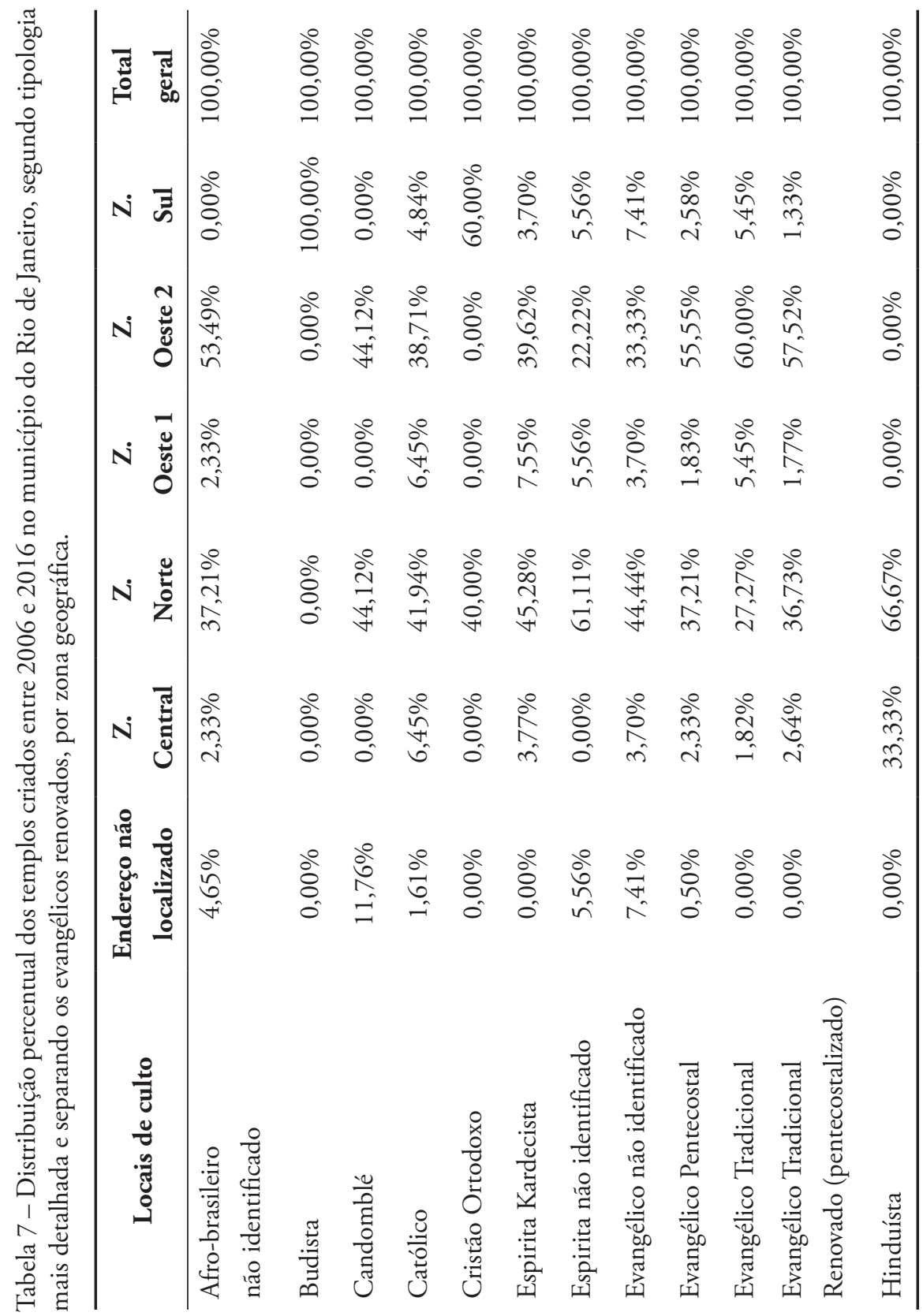

Debates do NER, Porto Alegre, ano i9, N. 36, P. 237-265, Ago./Dez. 20 i 9 


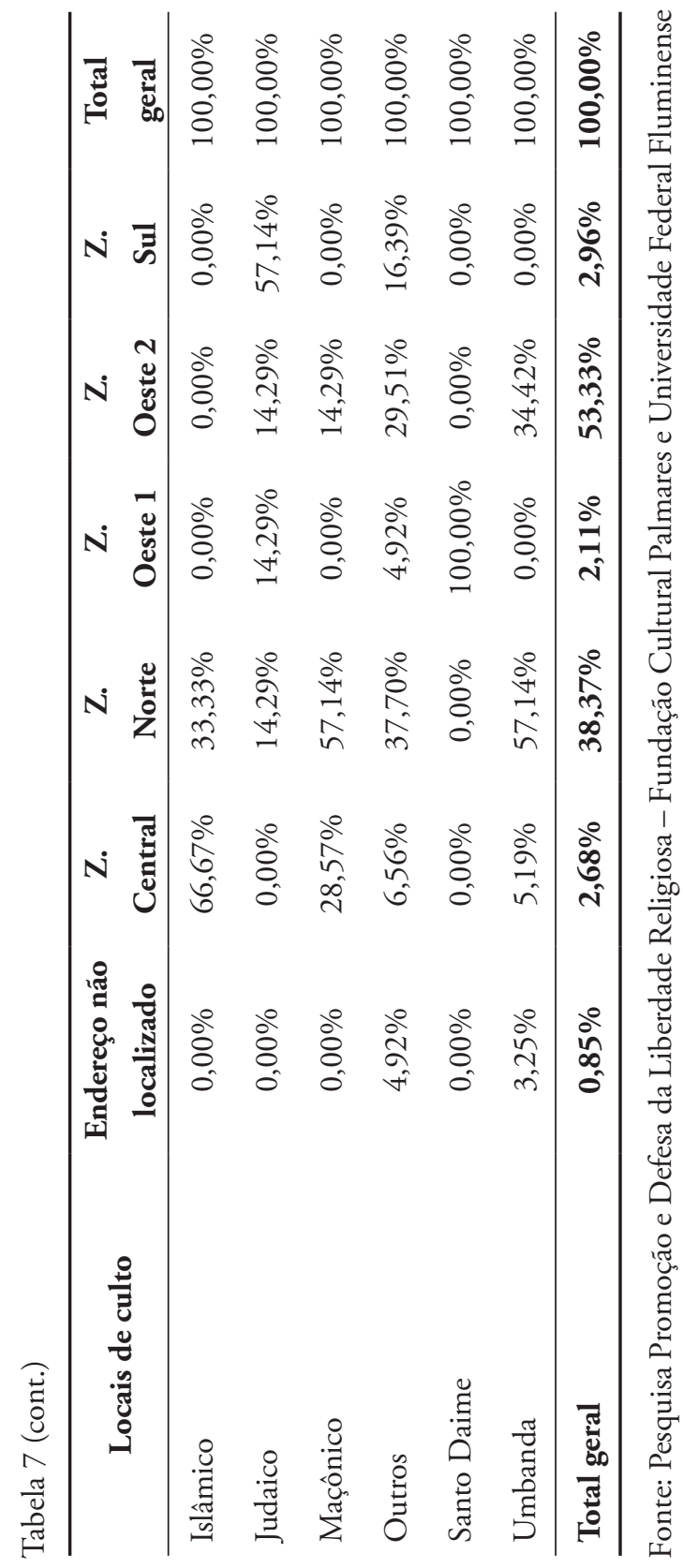

Debates do NER, Porto Alegre, ANo i9, N. 36, P. 237-265, Ago./Dez. 20 i 9 


\section{CONSIDERAÇÓES FINAIS}

O mapeamento realizado, apesar de ter detectado a criação de 3990 espaços de culto religioso entre 2006 e 2016 na cidade do Rio de Janeiro, certamente náo expressa integralmente a dinâmica de incremento de agregaçôes religiosas naquele espaço e tempo. Isto porque, as características da metodologia empregada limitam a coleta de dados àqueles agrupamentos que possuem algum nível de institucionalidade e, potencialmente, de continuidade no tempo, uma vez que buscaram inserção burocrática frente aos órgãos públicos.

É possível supor que uma miríade incalculável de outras agregações tenha vindo à luz no mesmo período. Apesar de ser necessário levar em conta este dado, os resultados gerais que conseguimos produzir a partir do banco de dados criado, corroboram tendências nacionais e mesmo as configuraçóes mais específicas do Estado do Rio de Janeiro e da Região Metropolitana, que podem ser observados nos censos demográficos. É claro que nos censos encontramos o número de fiéis enquanto que em nossa pesquisa nos dedicamos ao número de espaços de culto e sua dispersão pelo território da cidade.

Ao relacionar geografia e indicadores sociais de cada estado brasileiro, a pesquisa de Jacob et al. $(2006,2013)$ já nos revelava no contexto do estado do Rio de Janeiro, o crescimento dos evangélicos e a sua correlação com os problemas sociais e econômicos existentes nas grandes cidades, principalmente em espaços de periferia. Assim, como o georreferenciamento realizado por Almeida (2004) na regiáo metropolitana de São Paulo que localizou a predominância de igrejas da Assembleia de Deus nestes locais.

O mapeamento dos locais de culto no município do Rio de Janeiro realizado no âmbito do projeto "Liberdade Religiosa" se aproxima das perspectivas de análise acima no que diz respeito aos resultados, apesar da metodologia seguir caminhos diferentes. Do ponto de vista geográfico, os resultados que encontramos também corroboram análises mais gerais que indicam o predomínio de populaçóes mais pobres entre os adeptos das denominaçóes evangélicas pentecostais (Mariano, 2011). Como vimos na

Debates do NER, Porto Alegre, Ano i9, N. 36, P. 237-265, Ago./Dez. 20 i 9 
tabela 6 as classificaçôes evangélicas que mapeamos (exceto os evangélicos não identificados) apresentam maior percentual de criação de espaços de culto na região que denominamos como Zona Oeste 2. Esta parte da cidade do Rio de Janeiro é a única ainda considerada como de expansão e, portanto, tende a agregar em maior proporção características de urbanizaçáo recente ou incompleta que, pelo custo menor da moradia, atrai segmentos com renda mais baixa. O crescimento de templos nesta regiáo, com destaque para os evangélicos, revela que esta área de expansáo urbana (cujos interesses político e econômico são grandes) é também uma área de missão, de evangelização, de difusão de gramáticas, estéticas, de um ethos pentecostal (Mafra, 2011; Vital da Cunha, 2018).

\section{REFERÊNCIAS}

ALMEIDA, Ronaldo de. Religiáo na metrópole paulista. Revista Brasileira de Ciências Sociais, São Paulo, v. 19 n. 56, p. 15-27, 2004. Disponível em: http://www.scielo.br/pdf/rbcsoc/v19n56/a02v1956.pdf. Acesso em: 5 fev. 2019.

ALMEIDA, Ronaldo de; MONTEIRO, Paula. Trânsito religioso no Brasil. São Paulo em Perspectiva, São Paulo, v.15, n. 3, p. 92-100, 2001. ARQUIDIOCESE DE SÃO SEBASTIĀO DO RIO DE JANEIRO. Cúria Metropolitana. Anuário Eclesiástico. Rio de Janeiro: ArqRio, 2015. Disponível em: http://arqrio.org/curia/anuario/paroquias. Acesso em: 22 ago. 2017.

BRASIL. Lei no 10.825, de 22 de dezembro de 2003. Define organizaçôes religiosas e partidos políticos como pessoas jurídicas de direito privado. Diário Oficial da União, Brasília, DF, 23 dez. 2003. Disponível em: http://www. planalto.gov.br/ccivil_03/leis/2003/L10.825.htm. Acesso em: 18 ago. 2017. BRASIL. Receita Federal do Brasil. Tabela de documentos. Brasília, DF, [201-]. Disponível em: http://www.receita.fazenda.gov.br/pessoajuridica/ cnpj/tabelas/documentoseventos.htm. Acesso em: 18 ago. 2017. 
DIÁRIO OFICIAL DO MUNICÍPIO DO RIO DE JANEIRO. Rio de Janeiro: Imprensa da Cidade, 2006-2016. Disponível em: http://doweb. rio.rj.gov.br. Acesso em: 11 nov. 2017.

FERNANDES, Rubem. Censo Institucional Evangélico CIN 1992: primeiros comentários. Rio de Janeiro: NPE/ISER, 1992.

FONSECA, Denise; GIACOMINI, Sônia (org.) Presença do Axé: mapeando terreiros no Rio de Janeiro. Rio de Janeiro: Editora PUC-Rio, 2013.

FRESTON, Paul. Protestantes e Política no Brasil: da Constituinte ao Impeachment. 1993. Tese (Doutorado em Ciências Sociais) - Universidade Estadual de Campinas, Campinas, 1993.

GINZBURG, Carlo. Mitos, emblemas, sinais: morfologia e história. Tradução: Federico Carotti. São Paulo: Companhia das Letras, 1989.

GIUMBELLI, Emerson. A vida jurídica das igrejas: observaçóes sobre minorias religiosas em quatro países (Argentina, Brasil, México e Uruguai). Religião \& Sociedade, Rio de Janeiro, v. 37, n. 2, p. 121-143, 2017.

INSTITUTO BRASILEIRO DE GEOGRAFIA E ESTATÍSTICA (IBGE). Censo 2010: aglomerados subnormais. Rio de Janeiro: IBGE, 2010a. Disponível em: https://biblioteca.ibge.gov.br/index.php/biblioteca-catalogo?vie$\mathrm{w}=\mathrm{detalhes} \& \mathrm{id}=7552$. Acesso em: 11 nov. 2017.

INSTITUTO BRASILEIRO DE GEOGRAFIA E ESTATÍSTICA (IBGE). Censo 2010: características gerais da população, religiáo e pessoas com deficiência. Rio de Janeiro: IBGE, 2010b. Disponível em: https://biblioteca. ibge.gov.br/index.php/biblioteca-catalogo?view=detalhes\&id $=794$. Acesso em: 22 ago. 2017.

INSTITUTO PEREIRA PASSOS (IPP). Informaçôes sobre favelas e loteamentos - SABREN. Rio de Janeiro, 2014. Disponível em: http://www.rio. rj.gov.br/web/ipp. Acesso em: 11 nov. 2017. 
JACOB, Cesar Romero et al. Religiāo e sociedade em capitais brasileiras. Rio de Janeiro: Editora PUC-Rio; São Paulo: Loyola; Brasília, DF: CNBB, 2006. JACOB, Cesar Romero; HEES, Dora Rodrigues; WANIEZ, Philippe. Religiäo e território no Brasil: 1991/2010. Rio de Janeiro: Editora PUC-Rio, 2013. MAFRA, Clara. Censo da Religião: um instrumento dispensável ou reciclável? Religião \& Sociedade, Rio de Janeiro, v. 24, n. 2, p. 152-159, 2004. MAFRA, Clara. O problema da formação do "cinturão pentecostal" em uma metrópole da América do Sul. Interseçōes, Rio de Janeiro, v. 13, n. 1, p. 136-152, 2011.

MAFRA, Clara. Os evangélicos. Rio de Janeiro: Jorge Zahar, 2001.

MAFRA, Clara; ALMEIDA, Ronaldo (org.). Religiōes e cidades: Rio de Janeiro e São Paulo. São Paulo: Terceiro Nome, 2009.

MARIANO, Ricardo. Neopentecostais: sociologia do novo pentecostalismo no Brasil. São Paulo: Edições Loyola, 1999.

MARIANO, Ricardo. Sociologia do crescimento pentecostal no Brasil: um balanço. Perspectiva Teológica, Belo Horizonte, ano 43, n. 119, p. 11-36, jan./abr. 2011. Disponível em: http://faje.edu.br/periodicos/index.php/ perspectiva/article/view/1028/1449. Acesso em: 3 set. 18.

PIERUCCI, Antônio Flávio. Bye bye, Brasil: o declínio das religióes tradicionais no Censo 2000. Estudos Avançados, São Paulo, v. 18, n. 52, p. 17-28, 2004.

PIERUCCI, Antônio Flávio. Religiôes do Brasil em números. Ciência Hoje, Rio de Janeiro, v. 34, n. 199, p. 68-79, 2003.

PUC-RIO; SEASDH-RJ. Cartilha para legalização de casas religiosas de matriz africana. Rio de Janeiro: PUC-RIO; SEASDH-RJ, 2012.

REGO, Luiz Felipe G.; FONSECA, Denise P. R. da; GIACOMINI, Sônia Maria (org.). Cartografia social de terreiros no Rio de Janeiro. Rio de Janeiro: PUC-Rio, 2014. 
RIO DE JANEIRO (Município). Regiōes de Planejamento (RP), Regióes Administrativas (RA) e Bairros do Município do Rio de Janeiro. Data.Rio: Informaçóes sobre a Cidade, Rio de Janeiro, 2017. Disponível em: http:// www.data.rio/datasets/31d845e1c56a49c6a2b0e01420ec83b8. Acesso em: 11 nov. 2017.

SILVA JR., Hédio. Intolerância religiosa e direitos humanos. In: SANTOS, Ivanir dos; ESTEVES FILHO, Astrogildo (org.). Intolerância religiosa $X$ democracia. Rio de Janeiro: CEAP, 2009.

TEIXEIRA, Faustino; MENEZES, Renata (org.). As religióes no Brasil: continuidades e rupturas. Petrópolis: Vozes, 2006.

TEIXEIRA, Faustino; MENEZES, Renata (org.). Religioes em movimento: o Censo de 2010. Petrópolis: Vozes, 2013.

VITAL DA CUNHA, Christina. Pentecostal cultures in urban peripheries: a socio-anthropological analysis of Pentecostalism in arts, grammars, crime and morality. Vibrant: Virtual Brazilian Anthropology, Brasília, DF, v. 15, n. 1, p. 93-115, 2018.

WEBER, Max. A objetividade do conhecimento nas ciências sociais. In: COHN, Gabriel (org.). Max Weber: Sociologia. Rio de Janeiro: Ática, 1985.

Recebido em: 29/11/2018

Aprovado em: 22/02/2019 
